Revista de la red interuniversitaria de estudios sobre las literaturas rioplatenses contemporáneas en Francia

Un año. Literatura argentina 1969

\title{
La edición de literatura en la Argentina de fines de los sesenta
}

José Luis de Diego

(2) OpenEdition

Journals

Edición electrónica

URL: http://journals.openedition.org/lirico/3147

DOI: $10.4000 /$ lirico.3147

ISSN: 2262-8339

Editor

Réseau interuniversitaire d'étude des littératures contemporaines du Río de la Plata

\section{Referencia electrónica}

José Luis de Diego, "La edición de literatura en la Argentina de fines de los sesenta », Cuadernos LIRICO [En línea], 15 | 2016, Puesto en línea el 05 octubre 2016, consultado el 19 abril 2019. URL : http://journals.openedition.org/lirico/3147 ; DOI : 10.4000/lirico.3147

Este documento fue generado automáticamente el 19 abril 2019.

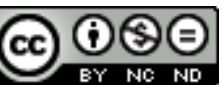

Cuadernos LIRICO está distribuido bajo una Licencia Creative Commons Atribución-NoComercialSinDerivar 4.0 Internacional. 


\title{
La edición de literatura en la Argentina de fines de los sesenta
}

\author{
José Luis de Diego
}

\section{Caracterización sumaria del mercado editorial}

1 La bibliografía sobre la industria editorial argentina ha consagrado la denominación «época de oro» para el período que va, aproximadamente, de 1938 a 1953. La causa más evidente de ese florecimiento fue la Guerra Civil de España: por un lado, editores peninsulares trasladan su experiencia al Río de la Plata; por otro, la industria española entra en un colapso que implica la pérdida casi total del mercado externo. De manera que Argentina se transforma en el principal proveedor de libros en nuestra lengua: se calcula que en esos años el 80\% de los libros que circulaban en España provenía de nuestro país. Colecciones de amplia difusión como la Biblioteca Contemporánea de Losada y la Colección Austral de Espasa-Calpe estaban dirigidas por editores españoles y los catálogos, con abundante presencia de autores españoles, ponían de manifiesto que habían sido proyectados pensando también en ese mercado. 1953, por lo tanto, se fija como el año límite de aquella bonanza, con más de 50 millones de ejemplares producidos $\mathrm{y}$ un promedio de tiraje que superaba los 10.000 ejemplares. El cuadro siguiente, que tiene ese año como punto de partida, permite observar la declinación durante los años posteriores, del ' 54 al ' 58 , y una suerte de amesetamiento durante la década de los años sesenta, con un leve crecimiento en la cantidad de títulos y en el tiraje promedio.

Cuadro: Producción editorial, 1953-1974'

\begin{tabular}{|l|l|l|l|}
\hline Año & Total de títulos & Total de ejemplares & Tiraje promedio \\
\hline
\end{tabular}




\begin{tabular}{|l|l|l|l|}
\hline 1953 & 4610 & 50.912 .597 & 11040 \\
1954 & 3185 & 27.230 .479 & 8549 \\
1955 & 2617 & 21.948 .402 & 8386 \\
1956 & 4610 & 18.290 .273 & 7551 \\
1957 & 2530 & 17.908 .234 & 7078 \\
1958 & 2623 & 14.950 .999 & 5471 \\
1959 & 3701 & 31.809 .006 & 8594 \\
1960 & 4063 & 34.825 .152 & 8571 \\
1961 & 3874 & 18.032 .447 & 4654 \\
1962 & 3323 & 17.565 .484 & 5286 \\
1963 & 3989 & 29.307 .954 & 7347 \\
1964 & 3319 & 19.305 .266 & 5813 \\
1965 & 3556 & 19.008 .382 & 5345 \\
1966 & 3738 & 22.301 .654 & 5966 \\
1967 & 3705 & 25.030 .492 & 6755 \\
1968 & 4185 & 29.609 .217 & 7075 \\
1969 & 4554 & 22.677 .915 & 4979 \\
1970 & 4689 & 31.482 .833 & 6714 \\
1971 & 4634 & 29.281 .228 & 6318 \\
1972 & 4639 & 30.880 .480 & 6656 \\
1973 & 4286 & 38.208 .983 & 8914 \\
1974 & 4906 & 49.640 .619 & 10118 \\
\hline
\end{tabular}

2 Jorge B. Rivera caracteriza al período 1962-1968 como de una incipiente "primavera» editorial, a la que los semanarios de la época amplificaron como «el boom del libro argentino ${ }^{2}$. Si revisamos algunas notas sobre el mercado editorial aparecidas en Primera Plana -el semanario más influyente por entonces-, advertimos, ya en los títulos, el paso de la desazón a la euforia: «Recargos, nubarrones y amenaza de emigración en el negocio editorial» (26 de febrero de 1963), «La Argentina donde reinan los libros» (26 de enero de 1965), «La danza de los millones» (5 de noviembre de 1968). Sin embargo, si los números indican un tibio repunte, pero de ningún modo una recuperación equivalente a la década del cuarenta ${ }^{3}$, la pregunta se torna evidente: ¿dónde está entonces el boom? Lo que existió en verdad fue una brutal caída de las exportaciones debido a la recuperación de la industria española: si para mediados de los años cuarenta se exportaban 24 millones de ejemplares, para inicios de los sesenta ese número se había reducido a 10 millones $^{4}$, de manera que las empresas argentinas debieron apostar al mercado interno como una forma de supervivencia; es más, podríamos decir que las que más crecieron y se consolidaron fueron las que -como la editorial Sudamericana- más rápido y con mayor énfasis apuntaron al mercado interno, en especial, al libro de autor argentino. Así, más que «boom del libro argentino», cabría hablar de un boom del libro de autor argentino y latinoamericano. En el campo de la literatura, se puede advertir que los catálogos se desespañolizan y se van latinoamericanizando en el marco de la irrupción, ya entrados los sesenta, de un público de lectores nuevo, mucho más atento a la literatura de nuestro continente. Rivera menciona la fuerte presencia que tenían en el mercado de los años 
cincuenta algunos best-sellers «internacionales» como Lin Yutang, A. J. Cronin, Pearl Buck, Virgil Georghiu o Erich Maria Remarque ${ }^{5}$. Ese espacio, por supuesto, no desaparece, y será reemplazado por autores como Morris West, Arthur Hailey o Guy des Cars; sin embargo, su peso relativo ira decayendo debido a la fuerte presencia de autores argentinos (Silvina Bullrich, Dalmiro Sáenz, Leopoldo Marechal, Julio Cortázar, Ernesto Sabato, Beatriz Guido, David Viñas, Marta Lynch) y latinoamericanos (Carlos Fuentes, Gabriel García Márquez, Augusto Roa Bastos, Miguel Ángel Asturias, José María Arguedas, Jorge Amado), los que aparecerán cada vez con mayor frecuencia en las anheladas listas de los más vendidos.

Como se ha afirmado repetidas veces, el llamado boom de la novela latinoamericana -que se solapa con el período en análisis- produjo un efecto de arrastre: autores y obras que habían tenido una tibia recepción en sus primeras ediciones aprovecharon el empuje de las ventas de las grandes figuras del boom y activaron su presencia en el mercado; me refiero a Juan Rulfo, Juan Carlos Onetti, Alejo Carpentier, entre otros. E incluso García Márquez, que gracias a la notable recepción de Cien años de soledad pudo reeditar sus obras anteriores a través de Sudamericana en tiradas de 20.000 ejemplares: Los funerales de la mamá grande en 1967, La hojarasca en 1968, El coronel no tiene quien le escriba en 1969. Ese mismo fenómeno se pudo advertir en Argentina, según lo analizó con agudeza Ángel Rama: ninguno de los tres libros de Cortázar anteriores a Rayuela habían merecido una reedición (Bestiario, 1951: 2.500 ejemplares; Las armas secretas, 1959: 3.000 ejemplares; Los premios, 1960: 3.000 ejemplares); todos ellos, aprovechando el empuje de la celebrada novela del ' 63 , se reeditan a partir de 1967 con un piso de 10.000 ejemplares al año ${ }^{6}$. Por su parte, Rivera señala que Adán Buenosayres debió esperar 17 años para que se agotara su primera edición (1948) de 3.000 ejemplares; la segunda edición (1966) vendió 10.000 ejemplares en seis meses ${ }^{7}$. Algo similar ocurrió con El túnel, también de 1948, cuyas ventas se multiplicaron arrastradas por el éxito de Sobre héroes y tumbas (1961). Como se ve, el boom del libro argentino tuvo también un efecto retroactivo, efecto acentuado cuando los escritores consagrados oficiaron de «descubridores» entusiastas de textos esquivos al mercado, tal y como lo hiciera tempranamente Julio Cortázar con la novela de Marechal, o con Paradiso de Lezama Lima, que editara De la Flor en el '68, acaso empujada por el panegírico de Cortázar incluido, un año antes, en La vuelta al día en ochenta mundos.

El crecimiento del mercado interno obedeció a una serie de razones que hemos explicado parcialmente y produjo algunos efectos novedosos. La caída de las exportaciones y, en consecuencia, la apuesta por el libro de autor argentino es una razón que explica la oferta, pero no alcanza a explicar la demanda. Seguramente, la demanda en ascenso se deba a las expectativas crecientes de una clase media ampliada que produjo, en su manifestación institucional, una explosión de la matrícula universitaria en la región ${ }^{8}$. Interesados cada vez más en la modernización cultural que proponían los semanarios de moda, como Primera Plana ${ }^{9}$, Panorama y Confirmado, y seducidos por la literatura de nuestro continente y el ensayismo que daba cuenta de la creciente radicalización política, la clase media de entonces -y en especial la juventud- se creyó protagonista de la inminencia de cambios sociales significativos $\mathrm{y}$, acaso sin proponérselo, se transformó en un mercado apetecible para las empresas editoriales. Y fue causa, como dijimos, de algunos efectos que marcaron el campo editorial de entonces. Por un lado, para captar ese mercado se multiplicaron las estrategias de venta. Sabemos que la venta de libros en kioscos, cigarrerías o estaciones de trenes era una práctica que en Argentina ya contaba con antecedentes desde principios de siglo; sin embargo, empujada por la presencia en la calle de los libros de Eudeba y los fascículos del Centro Editor de América Latina, la 
comercialización del libro en espacios no tradicionales fue una característica sobresaliente del período.

El otro efecto que es menester mencionar es la tendencia a la profesionalización de los escritores. Como ya ha sido demostrado, la profesionalización es un proceso de ciclo largo que se inicia en Europa hacia mediados del siglo XIX con los narradores que se suman a las estrategias de ampliación del público de los grandes periódicos a través de los folletines. Desde entonces y hasta hoy, el campo literario se ha visto envuelto en debates interminables, que a menudo se explicitan como alternativas dilemáticas, acerca de opciones éticas y estéticas diferentes respecto del mercado y del público. Manuel Gálvez, Roberto Payró y Horacio Quiroga se cuentan entre los primeros escritores que se plantearon su práctica como un oficio y como un medio de subsistencia. Si estamos, entonces, ante un ciclo largo, lo novedoso del período que nos ocupa es su aceleración, en un contexto cultural y comercial que obligó a los autores a acomodarse al éxito sin las herramientas adecuadas: debieron acostumbrarse a un ritmo de trabajo menos artesanal y más sujeto a la demanda; debieron aceptar entrevistas para medios masivos en los que se los interrogaba sobre conflictos sociales o determinadas coyunturas políticas; debieron ser tolerantes ante las estrategias de publicidad y a la visibilidad pública de sus figuras.

Ahora bien, si volvemos por un momento a los números del cuadro, advertimos que, luego de una baja hacia 1969, el mercado se recupera hasta lograr, en 1974, números semejantes a los de 1953, superando los 10.000 ejemplares de tiraje promedio. En 1976, Emilio Carilla afirmaba que «Desgraciadamente, este momento [fines de los sesenta] duró muy poco, y después del 70 la declinación fue notoria hasta culminar en los actuales días de crisis» ${ }^{10}$. Por su parte, Rodolfo Borello, un año después, alertaba sobre la crisis que vivía la industria: «el negocio editorial argentino se encuentra en crisis desde 1954 y la situación no parece haber mejorado hasta hoy. Es más, entre 1975 y 1976 se ha vuelto tan crítica que los últimos informes sobre las editoriales y el libro (como industria) no auguran un futuro brillante para la misma» ${ }^{11}$. No sabemos las razones que movían a Carilla y a Borello a afirmar esto -posiblemente, razones políticas, o el impacto reciente de las bruscas devaluaciones de 1975, o simplemente la falta de datos-, pero sí sabemos que estaban equivocados. El informe de Getino pone en evidencia que existió un crecimiento notable de la producción de libros posterior a la «época de oro» que reconoce en 1974 su pico más alto $^{12}$.

\section{Los sellos más importantes}

7 En el artículo ya citado que apareciera en Primera Plana hacia fines de 1968 ("La danza de los millones"), encontramos el siguiente diagnóstico respecto de las empresas editoriales:

Tres generaciones de editores comparten (y a veces disputan) el millonario y riesgoso negocio del libro. Son los Grandes Antiguos (sellos como Losada, Emecé, Sudamericana, Siglo Veinte, Santiago Rueda, Schapire, Sur, Troquel); la generación madura (Eudeba, Paidós, el Centro Editor de América Latina, Jorge Álvarez), y una generación recién llegada a la que asoman Galerna, Brújula, De la Flor, Carlos Pérez, ETCO, Del Candil.

8 A la distancia, aquel diagnóstico debiera corregirse, al menos parcialmente, ya que la suerte de aquellos sellos en algunos casos fue efímera, en otros se trató de proyectos que tuvieron visibilidad momentánea pero no acumularon capital simbólico significativo para seguir siendo recordados. No obstante, es interesante detenerse en alguno de esos 
proyectos editoriales para transformar, sumariamente, esa foto o mapa del '68, en una mirada diacrónica que les otorgue historia y sentido. Con el fin de precisar el alcance de los apartados que siguen, en cada caso, 1) he tomado como referencia el año 1969, proyectado hacia atrás y hacia adelante en un ciclo corto que va del '66 al '70;2) he focalizado el interés en la literatura argentina y latinoamericana (incluidos trabajos sobre literatura, significativos para nuestro campo); 3) las listas de libros son indicativas y no pretenden exhaustividad; sólo procuran ser un sustento para el análisis de las trayectorias de los sellos más significativos.

\section{Sudamericana}

1966: Haroldo Conti, Alrededor de la jaula; Julio Cortázar, Todos los fuegos el fuego; Luis Harss, Los nuestros; Juan José Hernández, Otro verano; Bernardo Kordon, Un día menos; Eduardo Mallea, El resentimiento; Leopoldo Marechal, Cuaderno de navegación; Daniel Moyano, Una luz muy lejana; Néstor Sánchez, Nosotros dos; Bernardo Verbitsky, Un noviazgo.

1967: Carlos Fuentes, Cambio de piel; Gabriel García Márquez, Cien años de soledad; Gabriel García Márquez, Los funerales de la mamá grande (nueva edición); Joaquín Gianuzzi, Las condiciones de la época; Alberto Girri, Envíos; Eduardo Mallea, La barca de hielo; Daniel Moyano, El fuego interrumpido; Manuel Mujica Lainez, Crónicas reales; Néstor Sánchez, Siberia Blues; Alberto Vanasco, Nueva York, Nueva York.

11 1968: Julio Cortázar, 62. Modelo para armar; Carlos Droguett, El hombre que había olvidado; Gabriel García Márquez, La hojarasca (nueva edición); Angélica Gorodischer, Las pelucas; Eduardo Mallea, La red; Daniel Moyano, El oscuro; Manuel Mujica Lainez, De milagros y de melancolías.

1969: Silvina Bullrich, Mañana digo basta; Antonio Di Benedetto, Los suicidas; Gabriel García Márquez, El coronel no tiene quien le escriba (nueva edición); Eduardo Mallea, La penúltima puerta; Tomás Eloy Martínez, Sagrado; Héctor Murena, Epitalámica; María Rosa Oliver, La vida cotidiana; Manuel Puig, Boquitas pintadas; Juan José Saer, Cicatrices; Néstor Sánchez, El amhor, los orsinis y la muerte; Rubén Tizziani, Las galerías.

1970: Julio Cortázar, Los reyes ( $2^{\mathrm{a}}$ edición); Julio Cortázar, Relatos; Alberto Girri, Casa de la mente; Alberto Girri, Antología temática; Marta Lynch, Cuentos de colores; Leopoldo Marechal, Megafón o la guerra; Héctor Murena, Policuerpón; Silvina Ocampo, Los días de la noche; María Elena Walsh, Dailan Kifki.

14 La cita de Primera Plana que acabamos de mencionar continúa así: «A la cabeza del pelotón marcha el primero de los Grandes Antiguos que supo modernizarse a tiempo: Sudamericana». El contraste que la afirmación implica respecto de los otros «Grandes Antiguos» es evidente, en especial con relación a Losada y Emecé, las tres editoriales tradicionales -fundadas en la coyuntura favorable del '38-'39- que ocuparon un lugar central en el mercado editorial argentino a lo largo de más de treinta años: mientras Sudamericana «supo modernizarse», las otras dos fueron quedando relegadas. Antonio López Llausás llegó a Argentina en 1939 y se hizo cargo de la empresa junto a Julián Urgoiti; desde entonces, Sudamericana fue siempre identificada como una empresa familiar: López Llausás; luego su hijo Jorge López Llovet; luego su nieta Gloria López Llovet de Rodrigué. «De la mano de López Llausás, que fue comprando acciones de la editorial hasta prácticamente dirigir solo sus destinos, hacia 1969 Sudamericana había 
convertido su capital inicial (400 mil pesos) en más de cien millones; tenía un fondo editorial de más de 1500 títulos y ocupaba el cuarto lugar en el país en cuanto a ventas» ${ }^{13}$.

Si se analiza un catálogo de la editorial de mediados de los cuarenta, llama la atención la casi inexistencia de autores argentinos; sobresale la colección Horizonte, un conjunto de 45 novelas de las cuales una es española (Baroja) y una argentina (Mallea, Las águilas); el resto son traducciones. Solo una página del catálogo está dedicada a la colección Laberinto en la que se mencionan dos títulos: la célebre Antología de la literatura fantástica, de Borges, Bioy Casares y Silvina Ocampo, y una Antología poética, en la que se presentan «los más bellos poemas argentinos de este siglo». El apartado «Poesía» sí incluye a autores nacionales: de 6 títulos, 4 corresponden a Francisco L. Bernárdez, Leopoldo Marechal, Juan R. Wilcock y Enrique Molina. Así, la colección Narrativa Argentina -en la que se incluyeron pocos años después Adán Buenosayres (1948), El túnel (1948), Bestiario (1951) y Misteriosa Buenos Aires (1951)-, aún no figuraba en el catálogo de 1945. De manera que es hacia fines de los cuarenta e inicios de los cincuenta en que se produce el arriesgado golpe de timón en dirección a la literatura nacional: y la apuesta salió bien, ya que los autores iniciales de la colección conformarían, unos quince años después, el nuevo «Parnaso» literario argentino de los sesenta: Marechal, Sabato, Cortázar. El dinamismo de la empresa para conseguir autores y títulos se advierte a comienzos de la década, cuando consigue quedarse con Sobre héroes y tumbas -que había sido editada por Fabril en 1961-; y al final de la década, cuando, a poco de lanzar Jorge Álvarez la primera novela de Manuel Puig, la segunda edición -y la segunda novela, Boquitas pintadas- tienen el sello de Sudamericana.

De entre los directivos y asesores de la editorial, se destaca la figura de Francisco Porrúa, «director del Departamento Literario» -a quien se le atribuyen los «descubrimientos» de Julio Cortázar, Alejandra Pizarnik y Cien años de soledad ${ }^{14}$. De la novela de García Márquez lanzaron en 1967 una primera edición de 8.000 ejemplares y a los quince días hubo que sacar una segunda edición; según el entonces gerente del sello, Fernando Vidal Buzzi, se vendieron 150.000 ejemplares en el primer año. Otra innovación de Sudamericana fue el haber publicado tempranamente ediciones de bolsillo: en 1958 comienza a salir la colección Piragua, en la que se reeditaban los éxitos de venta en formato mayor, en tiradas de más de 10.000 ejemplares. Pero si prescindimos por un momento de los títulos de mayor repercusión en las ventas, existen otras apuestas que contarán con un reconocimiento futuro: la persistencia en la publicación de un autor «de culto» como Néstor Sánchez; las dos primeras novelas de Daniel Moyano; la primera edición de Cicatrices, de un Juan José Saer que a partir de los ochenta ingresará al canon de nuestras letras y ocupará allí un lugar indiscutido.

\section{Losada}

17 1966: Enrique Molina, Las bellas furias; Augusto Roa Bastos, El baldío; Albert Camus, Carnets; Jean-Paul Sartre, El ser y la nada.

1967: Jorge Luis Borges y Adolfo Bioy Casares, Crónicas de Bustos Domecq; Carlos Drummond de Andrade, Mundo, vasto mundo; Amalia Jamilis, Detrás de las columnas; Luisa Mercedes Levinson, La pálida rosa de Soho; Ezequiel Martínez Estrada, Para una revisión de las letras argentinas; Pablo Neruda, La barcarola; Olga Orozco, La oscuridad es otro sol.

1968: Miguel Ángel Asturias, Week-end en Guatemala; Oliverio Girondo, 20 poemas... Calcomanías; Oliverio Girondo, Persuasión de los días; Oliverio Girondo, Obras; Eduardo 
Gudiño Kieffer, Para comerte mejor; Pablo Neruda, Las manos del día; Emir Rodríguez Monegal, El desterrado. Vida y obra de Horacio Quiroga; Ernesto Sabato, Tango, discusión y clave.

1969: Jorge Amado, Doña Flor y sus dos maridos; Jorge Amado, Gabriela, clavo y canela; Miguel Ángel Asturias, Viernes de dolores; Juana de Ibarbourou, Las lenguas de diamante; Pablo Neruda, Fin de mundo.

1970: José María Arguedas, Todas las sangres I y II; Beatriz Guido, Escándalos y soledades; Pablo Neruda, Las piedras del cielo; Pablo Neruda, La espada encendida.

Losada contaba, para comienzos de los sesenta, con el catálogo más prestigioso del país, en el amplio abanico que va de la literatura argentina y latinoamericana a la literatura traducida, del «gran teatro del mundo» a la notable biblioteca filosófica que dirigía Francisco Romero, de la vanguardia poética española a los inicios de la lingüística estructural. En otro lugar procuré analizar las razones de un declive que ya para los sesenta se tornaba evidente ${ }^{15}$. Algunos datos resultan muy significativos. Es sabido que el sello da a conocer, en primeras ediciones, La invención de Morel (1940) y El aleph (1949); sin embargo, Bioy solo visitará una vez más el catálogo de Losada, con El sueño de los héroes, de 1954; y Borges iniciará, hacia 1953, su estrecha relación con la Editorial Emecé, que será casi exclusiva hasta su muerte en 1986. En 1951, en un varias veces comentado episodio, Guillermo de Torre, director editorial del sello, desaconseja la publicación de La hojarasca, la primera novela de García Márquez. Jorge Lafforgue, quien fuera asesor literario de la empresa, cuenta un diálogo que sostuvo con Gonzalo Losada años después: «Tenía un número de Tel Quel que estaba saliendo en ese momento dedicado a Roland Barthes, voy y le digo al viejo Losada, 'mire, este es un pollo que... (risas) en Francia la está rompiendo, podemos traducirlo'. Me dijo que era interesante, y me llamó después y me dijo 'mire, Lafforgue, está muy bien su propuesta, pero nosotros tenemos a Sartre...'. Al poco tiempo empezó a ser traducido por Nicolás Rosa en Jorge Álvarez» ${ }^{16}$. Las tres referencias (perder autores como Borges y Bioy, García Márquez, Roland Barthes) pretenden ser ilustrativas de un proceso de declinación que no es sencillo explicar. La mayoría de los testimonios (y entre ellos el del propio Lafforgue, que trabajó largos años para la editorial) dan cuenta de un cambio significativo hacia 1955. La caída del peronismo posibilitó el ingreso a las universidades de buena parte del grupo fundacional, de donde la coherencia inicial se fue resquebrajando; además, la muerte de algunos de ellos (Henríquez Ureña en 1946, Amado Alonso en 1952, Lorenzo Luzuriaga en 1959) fuerza un recambio generacional. En esa coyuntura, cobraron más fuerza las decisiones del propio Losada (sin mediación de los especialistas que dirigían las colecciones) y creció el peso relativo, en esas decisiones, del departamento comercial. Todo parece indicar que al no haber podido, o sabido, redireccionar las políticas editoriales de la empresa hacia el movimiento de modernización literaria y cultural que algunos autores encarnaban, Losada inició su declive. Sin embargo, aún contaba con firmas de prestigio y buenos niveles de ventas como Miguel Ángel Asturias, el brasileño Jorge Amado, José María Arguedas, y el siempre vigente y prolífico Pablo Neruda ${ }^{17}$. En una referencia a los «best sellers 1964» aparecida en el semanario Primera Plana el 26 de enero de 1965, se afirma que El incendio y las vísperas, la novela de Beatriz Guido, había vendido 10.000 ejemplares en cinco semanas, y que el otro suceso de la editorial fue Jean-Paul Sartre y Las palabras, que vendió 6.000 en solo dos semanas ${ }^{18}$. Ya para los años sesenta, según lo ha comentado el gran editor que fue Javier Pradera $^{19}$, hubo intentos de compra de la empresa, pero Losada se negó a venderla y se mantuvo al frente hasta su muerte en 1981. 


\section{Emecé}

1967: Adolfo Bioy Casares, El gran serafín.

1969: Adolfo Bioy Casares, Diario de la guerra del cerdo; Jorge Luis Borges, Elogio de la sombra ; Jorge Luis Borges, Obra poética.

1970: Jorge Luis Borges, El informe de Brodie.

La lista que antecede resulta bien ilustrativa: pareciera que la relación de Emecé con la literatura argentina se hubiera limitado a sus dos figuras emblemáticas, Borges y Bioy Casares. La publicación en 1951 de La muerte y la brújula, de Jorge Luis Borges, da inicio a la edición sistemática del autor argentino que el sello suele exhibir con orgullo. No obstante, la relación con Borges había empezado antes, ya que en febrero de 1945 se lanza El Séptimo Círculo, una colección de novelas policiales que dirigieron Borges y Bioy Casares hasta 1955; en once años seleccionaron ciento diez títulos, la mayoría de ellos de origen anglosajón, y llegaron a editar un promedio de 18.000 ejemplares por título. Para el período que nos ocupa, se destacan la aparición de Diario de la guerra del cerdo de Bioy y la Obra poética de Borges, en 1969; y El informe de Brodie en el '70. Unos años después, en 1974, Emecé dará a conocer el emblemático tomo verde de las Obras completas de Borges.

Como afirma de Sagastizábal, Emecé elaboró un catálogo «de corte más clásico, dirigido a las clases altas y cultas, con una definida orientación hacia lo anglófilo y el pensamiento católico ${ }^{20}$. Con el tiempo, se fue acercando cada vez más a un best-sellerismo indisimulado; así se advierte en su colección de mayor popularidad, Grandes Novelistas, que aparece en 1948 con El extranjero, de Albert Camus, y Los idus de marzo, de Thornton Wilder. Si la colección en un primer momento albergó en su catálogo a Kafka y Faulkner, a Moravia, Hemingway y Cela, más adelante, y en especial hacia los sesenta, se multiplicaron los autores de títulos mediocres pero de gran llegada masiva: Arthur Hailey, Erich Segal, Guy des Cars, Leon Uris, Henri Charrière, Wilbur Smith. Por esos años, se profundiza la relación literatura y cine, en la que la venta de la novela se potencia con el éxito de la película, tal como ocurrió con Aeropuerto de Hailey, Love Story de Segal y Papillon de Charrière. En 1984, Ángel Rama se refería a Emecé en estos términos: "una editorial en que hicieron su obra Jorge Luis Borges, Adolfo Bioy Casares, Eduardo Mallea, donde se incorporó al español mucho de la mejor literatura anglosajona, constituyéndose en la guía modernizadora del lector hispanoamericano, se ha transformado en una adocenada productora de novelas baratas internacionales" ${ }^{21}$.

\section{Centro Editor de América Latina}

Serie del Encuentro (a partir de 1967; dirección de Horacio Achával y Susana Zanetti): incluyó 43 títulos, generalmente en segundas ediciones, de Macedonio Fernández, Roger Pla, César Tiempo, Antonio Di Benedetto, Haroldo Conti, Marta Lynch, David Viñas, Daniel Moyano, Enrique Wernicke, Bernardo Kordon, entre otros.

28 Capítulo. Historia de la Literatura Argentina (a partir de 1967; dirección de Roger Pla y Adolfo Prieto): incluyó 59 fascículos acompañados por un libro que conformaban la Biblioteca Argentina Fundamental. Si bien la colección estuvo dirigida a recuperar textos clásicos en ediciones económicas, alrededor de 15 títulos, correspondientes a "Los 
nuevos", fueron de autores contemporáneos (Mallea, Marechal, Sabato, Viñas, Castillo, Rozenmacher, Moyano).

Enciclopedia Literaria (a partir de 1967; dirección de Aníbal Ford y Nora Dottori): incluyó 49 títulos en pequeños volúmenes dedicados a la crítica literaria sobre autores y géneros de España e Hispanoamérica, y 11 títulos sobre teoría y crítica literaria ${ }^{22}$.

La Editorial de la Universidad de Buenos Aires (Eudeba) se fundó en 1958 y solo en ocho años desarrolló una vertiginosa actividad editorial mediante un catálogo de calidad y de alcance popular. El golpe militar de 1966 y la intervención de las universidades abortó el proyecto; para ese año, se calcula que Eudeba había editado un título por día y un total de once millones de ejemplares. Boris Spivacow -quien comandaba el proyecto- $y$ su equipo renunciaron y al poco tiempo, el 21 de setiembre de 1966, dieron inicio al Centro Editor de América Latina (CEAL), un nuevo proyecto editorial y cultural que continuó buena parte de las iniciativas que habían caracterizado a Eudeba. A poco de comenzar sus actividades, el CEAL firmó un acuerdo con la Cooperativa de Vendedores de Diarios, Revistas y Afines, y comenzó a distribuir el material producido en los kioscos del país y de grandes capitales de América Latina. El formato «un fascículo + un libro» logró un rápido interés en el público y se multiplicaron las colecciones: Capítulo. Historia de la Literatura Argentina (publicada junto con la Biblioteca Argentina Fundamental), Capítulo. Historia de la Literatura Mundial (publicada junto con la Biblioteca Básica Universal), Enciclopedia Literaria, Los Hombres de la Historia, Mi País tu País, Siglomundo. La Historia Documental del Siglo XX, Capítulo. Narradores de Hoy, Historia del Movimiento Obrero, Transformaciones, etc. Otra vez, la combinación de alta calidad de los contenidos (garantizado por un notable equipo de colaboradores) y un muy bajo costo de venta redundaron en el éxito de la empresa; éxito que hay que medir mucho más en cuanto a su impacto cultural que en cuanto a los beneficios económicos que produjo. Así, Eudeba primero y el CEAL después marcaron una época en la que eran posibles emprendimientos editoriales que atendieran más a la cultura que al dinero, y en la que confluyeron una generación de intelectuales comprometidos con los proyectos y una buena parte de la clase media en ascenso que encontró en aquellos libros los instrumentos más idóneos para su formación.

31 A fines de 1966, aparece la primera colección, Serie del Encuentro, cuarenta y tres títulos de autores argentinos. Su importancia fue doble: por reeditar autores y títulos de indudable calidad, y por hacerlo en libros de alcance popular y bajo costo. Muchos conocimos por primera vez y en aquel formato a Papeles de recienvenido de Macedonio Fernández, Historia de perros de Leónidas Barletta, Rosaura a las diez de Marco Denevi, Zama de Antonio Di Benedetto, Cayó sobre su rostro de David Viñas, Con otra gente de Haroldo Conti, "El monstruo" y otros cuentos de Daniel Moyano, La ribera de Enrique Wernicke, El río oscuro de Alfredo Varela. "Era una colección extraordinaria», ha dicho Beatriz Sarlo, «porque con ella mucha gente construía su cultura literaria. Nosotros mismos leímos allí muchos de esos títulos por primera vez» ${ }^{23}$.

También en 1967 apareció la colección Capítulo Argentino, dirigida por Roger Pla, con la asesoría de Adolfo Prieto: cada semana se comercializaba un fascículo, acompañado por un libro, hasta completar la Historia de la literatura argentina, en tres tomos, más 59 volúmenes de formato pequeño que formaban la Biblioteca Argentina Fundamental. Las historias de la literatura argentina aparecidas hasta entonces (la escrita por Ricardo Rojas y la dirigida por Rafael Alberto Arrieta) tenían un perfil académico y estaban orientadas a una clase ilustrada con competencias formadas en la universidad. En este caso, el modo de 
comercialización, el fácil acceso y la amplia difusión lograron poner en manos de muchos, a la vez, una historia en fascículos y una biblioteca, sin ceder en el necesario rigor crítico e histórico del proyecto. Un año después, con la dirección de Luis Gregorich, comienza a publicarse Capítulo Universal, 158 fascículos, cada uno con su respectivo libro, que completaron 15 tomos de Historia de la Literatura Universal y la Biblioteca Básica Universal ${ }^{24}$ . Se ha debatido hasta qué punto las políticas de edición del CEAL constituyeron una continuidad respecto de Eudeba o cuáles fueron las líneas de diferenciación y de cambio. Si el ritmo de producción, el bajo costo de los productos, el amplio alcance en el público y la centralidad del proyecto cultural por sobre los beneficios económicos enlazan las políticas del CEAL con las de su antecesora; se advierten también algunas novedades: un mayor interés en las temáticas nacionales y latinoamericanas y, acorde con los tiempos, un creciente proceso de radicalización ideológica ${ }^{25}$.

\section{Jorge Álvarez}

1966: Abelardo Castillo, Cuentos crueles; Liliana Heker, Los que vieron la zarza; Bernardo Kordon, Reina del Plata; Adolfo Prieto, La literatura autobiográfica argentina; Francisco Urondo, Todo eso; Bernardo Verbitsky, Un hombre de papel; David Viñas, En la semana trágica

1967: Roland Barthes, El grado cero de la escritura; Aníbal Ford, Sumbosa; Marta Lynch, La señora Ordoñez; Juan Carlos Martelli, Persona pálida; Tununa Mercado, Celebrar a la mujer como a una pascua; Ricardo Piglia, La invasión; David Viñas, Del apogeo de la oligarquía a la crisis de la ciudad liberal: Laferrère; Rodolfo Walsh, Un kilo de oro.

1968: Crónicas de Latinoamérica, Crónicas de Chile; Germán García, Nanina; Noé Jitrik, El 80 y su mundo; Bernardo Kordon, Hacele bien a la gente; Oscar Masotta, Conciencia y estructura; Jorge B. Rivera, La primitiva literatura gauchesca; Manuel Puig, La traición de Rita Hayworth ( $2^{\mathrm{a}}$ ed.: Sudamericana, 1970); Eliseo Verón (ed.) Conducta, estructura y comunicación.

1969: Crónicas de Cuba; Abelardo Castillo, Las otras puertas; Germán García, Cancha Rayada; Noé Jitrik, Los viajeros; Mario Szichman, Crónica falsa; Rodolfo Walsh, Operación masacre (3a ed.).

Cuando se habla de sellos editoriales de los sesenta el primer nombre que suele mencionarse es el de Jorge Álvarez. Por un lado, porque es el representante más emblemático de una nueva generación de editores: jóvenes intelectuales apasionados por los libros que no estaban demasiado habituados a las estructuras comerciales ni a las demandas del mercado. Por otro, porque allí, en su editorial, se formaron otros editores más jóvenes de larga trayectoria en el campo, como Daniel Divinsky y Guillermo Schavelzon, y trabajaron junto con él figuras relevantes del mundo intelectual como Rodolfo Walsh, Pirí Lugones, Julia Constenla y Rogelio García Lupo. En tercer lugar, porque, aunque su duración fue solo de siete años (del '63 al '69), dejó una marca en el mundo editorial de entonces por el carácter innovador de sus propuestas estéticas e ideológicas. Hoy casi nadie discute que Manuel Puig, Juan José Saer y Ricardo Piglia ocupan un lugar central en nuestro canon más o menos reciente; no parece una mera coincidencia que los tres hubiesen publicado algunos de sus primeros textos en Jorge Álvarez: Responso (1964), La invasión (1967) y La traición de Rita Hayworth (1968). La mayor visibilidad la obtuvo con la serie Crónicas... (colección dirigida por Julia Constenla), 21 textos antológicos reunidos bajo títulos genéricos: Crónicas del amor, Crónicas del pasado, 
Crónicas de la burguesía, Crónicas de América, etc. En declaraciones a Primera Plana (5 de noviembre de 1968), Álvarez decía que

El pago de los derechos a los escritores que intervinieron en las Crónicas fue una madeja que variaba de color: en la mayoría de los casos, les entregué una suma fija, que osciló entre los 5 y los 50 mil pesos, según el grado de amistad y confianza. A veces supe que un amigo necesitaba unos pesos: entonces, por mi cuenta, subía la prima. Otros autores me regalaron sus cuentos: entre ellos, Cortázar, García Márquez, Sábato, Beatriz Guido.

La misma nota afirma que de las Crónicas vendió unos 400.000 ejemplares. Además, el sello hizo una apuesta fuerte por la modernización cultural mediante la traducción de un texto decisivo como El grado cero de la escritura y la publicación de las primeras obras de Oscar Masotta y Eliseo Verón, entre otros, quienes comenzaban a hablar de estructuralismo, de comunicación, de happenings, de historietas.

Según numerosos testimonios, su local en Talcahuano 485 se transformó en un «cenáculo» ${ }^{26}$ de la sociabilidad intelectual de entonces, rodeado, a la distancia, de un aura mítica amplificada por un anecdotario infinito. En 2012, la Biblioteca Nacional reconoció la trayectoria de Álvarez mediante la edición de su catálogo completo y un año después Libros del Zorzal publicó sus Memorias ${ }^{27}$. En uno de los textos que abre el catálogo, afirma Guillermo David:

La irrupción de Jorge Álvarez en el panorama cultural argentino significó una revolución en la lengua, la música y la cultura. El habla plebeya de una nueva generación de escritores -los hijos del peronismo clásico- hacía su ingreso con potestad irreverente en la literatura de consumo masivo a través de los libros que publicaba bajo el auspicio -y el riesgo- de su nombre..$^{28}$

\section{De la Flor, Galerna, Tiempo Contemporáneo}

1967: Jorge Di Paola, ¡Minga! (De la Flor); V. A., El libro de los autores (De la Flor); David Viñas, Los años despiadados (De la Flor, $2^{\circ}$ ed.); Germán Rozenmacher, Los ojos del tigre (Galerna); Juan José Saer, Unidad de lugar (Galerna).

41 1968: José Lezama Lima, Paradiso (De la Flor); Enrique Wernicke, El agua (De la Flor); Adolfo Bioy Casares, La otra aventura (Galerna); Francisco Urondo, Veinte años de poesía argentina, 1940-1960 (Galerna); Enrique Wernicke, Cuentos (Tiempo Contemporáneo).

1969: Leopoldo Marechal, Antología poética (De la Flor); Isidoro Blaistein, La felicidad (Galerna); Antonio Di Benedetto, Cuentos claros (Galerna); Juan Gelman, Los poemas de Sidney West (Galerna); Héctor Lastra, De tierra y escapularios (Galerna); Juan Carlos Martini, El último de los onas (Galerna); Adolfo Prieto, Estudios de literatura argentina (Galerna); Héctor Tizón, Fuego en Casabindo (Galerna); David Viñas, Cosas concretas (Tiempo Contemporáneo); Rodolfo Walsh, ¿Quién mató a Rosendo? (Tiempo Contemporáneo).

1970: Noé Jitrik, Ensayos y estudios de literatura argentina (Galerna); Nicolás Rosa, Crítica y significación (Galerna); Nicolás Casullo, Para hacer el amor en los parques (Tiempo Contemporáneo).

Por razones de espacio, agrupamos aquí tres sellos que, como ya en parte adelantamos, tienen un origen en común: surgieron como desprendimientos de Jorge Álvarez, empujados y apoyados por el editor, quien seguramente buscaba multiplicar la competencia con el fin de fortalecer ese espacio del mercado. Ediciones de la Flor se funda en 1966 y comienza a editar en 1967; se trata de una de las pocas editoriales 
independientes surgida en los sesenta que subsiste en la actualidad con los mismos propietarios, Daniel Divinsky y Ana María Miler. Casi por azar, desarrolló un fondo editorial que se caracteriza por hacer foco en el humor gráfico: después de publicar las primeras cinco entregas de Mafalda en Jorge Álvarez, Quino entró en litigio con el editor por falta de pago, y recaló, para su defensa, en el estudio de abogados de Divinsky y Finkelberg. Quino decidió entonces publicar Mafalda 6 en De la Flor, de la que se vendieron 200.000 ejemplares en dos días. Entusiasmado por el éxito de los libros de cómics, aún hoy Divinsky atribuye a ese género las razones de su subsistencia ${ }^{29}$. Uno de los grandes aportes a la literatura de nuestra lengua fue la publicación, en aquellos años, de Paradiso, la novela del cubano Lezama Lima. En palabras de Divinsky: «Nadie podría haber previsto que, a partir de la recomendación entusiasta hecha por Cortázar [...] pero sobre todo del reportaje al autor realizado por Tomás Eloy Martínez para la entonces todopoderosa Primera Plana que fue anunciado como un logro periodístico sin precedentes, la primera edición se vendería... en una sola tarde» ${ }^{30}$.

«En tanto editorial, creemos que no se puede hacer una historia cultural del país sin tener en cuenta la influencia de Galerna», se afirma con orgullo en el sitio de internet del sello. Y agregan: «hemos publicado a escritores de la talla de Osvaldo Bayer, Adolfo Bioy Casares, Juan Martini, Jorge Asís, Germán Rozenmacher, Juan José Saer, Héctor Tizón, Abelardo Castillo, Enrique Medina, Osvaldo Pellettieri y Vlady Kociancich». Parte fundamental de la nueva generación de editores, Guillermo Schavelzon se inicia muy joven en Jorge Álvarez, luego se independiza y funda su propio sello, Galerna, con la colaboración del destacado crítico uruguayo Ángel Rama, quien por entonces dirigía la Editorial Arca de Montevideo. Galerna dio a conocer títulos muy significativos en el contexto de emergencia de una nueva generación de escritores: la primera novela de Héctor Tizón, el primer libro de Isidoro Blaisten, el segundo libro de cuentos de Germán Rozenmacher (el primero, Cabecita negra, lo había publicado Álvarez en 1963), uno de los poemarios más destacados de Juan Gelman, la indispensable antología poética que preparó Francisco Urondo. Además, con el sello se consolidó una generación crítica de vasta influencia en nuestro país: Noé Jitrik, Adolfo Prieto, Nicolás Rosa. Por último, no es un dato menor que Galerna fue quien editó una de las revistas sobresalientes del período, Los Libros, que comienza a salir en julio de 1969 con la dirección de Héctor Schmucler ${ }^{31}$.

Como en el caso de Ediciones de la Flor, el proyecto editorial de Tiempo Contemporáneo también estuvo encabezado por dos abogados, Alberto Serebrisky y Natalio Wisniacki, y ocupó un lugar preponderante en lo que podríamos llamar la red de editoriales de la nueva izquierda. A diferencia de Jorge Álvarez, Tiempo Contemporáneo fue una iniciativa en la que la primacía de lo cultural e ideológico no daba lugar al éxito económico. De hecho, sus fundadores han insistido en que siempre debían poner más dinero y nunca podían retirar dividendos. Las dos figuras más importantes del proyecto editorial fueron Ricardo Piglia y Eliseo Verón. Desde la colección Ficciones, Piglia publicó a Kordon, Viñas, Wernicke y Casullo junto con autores de la vanguardia literaria de Estados Unidos, y en la colección Mundo Actual, se destacó la controversial ¿Quién mató a Rosendo?, de Rodolfo Walsh -el primer, y uno de los pocos, éxito de venta de la editorial. En 1969 se alcanzaron a publicar los dos primeros títulos de la Serie Negra, también dirigida por Piglia (A todo riesgo de José Giovanni y ¿Acaso no matan a los caballos? de Horace McCoy); de la colección aparecieron en total 21 títulos y dejó de salir en 1977, con el cierre de la editorial. Por su parte, la labor de Verón fue decisiva en la dirección de las colecciones Análisis y Perspectivas, y en la muy difundida Comunicaciones, en la que se tradujeron varios 
números de la revista francesa Communications: La semiología, Lo verosímil, Análisis estructural del relato, Investigaciones retóricas, entre otras (aunque las fechas de publicación, claro está, son posteriores al período que nos ocupa).

\section{Seix Barral / Siglo XXI}

1966: Carlos Martínez Moreno, Con las primeras luces (Seix Barral); Aldo Pellegrini, Antología de la poesía viva latinoamericana (Seix Barral); Mario Vargas Llosa, La casa verde (Seix Barral); Fernando Del Paso, José Trigo (Siglo XXI); Ezequiel Martínez Estrada, Martí: el héroe y su acción revolucionaria (Siglo XXI).

1967: Guillermo Cabrera Infante, Tres tristes tigres (Seix Barral); Miguel Ángel Asturias, El espejo de Lida Sal (Siglo XXI); Julio Cortázar, La vuelta al día en ochenta mundos (Siglo XXI); Carlos Fuentes, Zona sagrada (Siglo XXI).

1968: Julio Cortázar, Ceremonias (Seix Barral); David Viñas, Los hombres de a caballo (Siglo XXI).

1969: Julio Cortázar, Último round (Siglo XXI); Mario Vargas Llosa, Conversación en La Catedral (Seix Barral).

1970: José Donoso, El obsceno pájaro de la noche (Seix Barral).

Para cerrar el panorama sobre los principales sellos, debo mencionar dos editoriales extranjeras que han tenido una notable influencia en la difusión y consolidación de autores, obras y poéticas. Carlos Barral fue uno de los editores míticos de la España franquista. Es un lugar común afirmar que Barral, respaldado por una sólida cultura cosmopolita, encarnó la vanguardia literaria de aquellos años y fue maestro y guía de editores más jóvenes; es también un lugar común escuchar que era un mal administrador y que confiaba demasiado en sus intuiciones. En 1962 Seix Barral puso en marcha el premio Biblioteca Breve $\mathrm{y}$, a través de él, será el protagonista indiscutido de la incorporación al mercado español del llamado boom de la novela latinoamericana. A partir de entonces, dio a conocer las grandes novelas de Vargas Llosa de los sesenta y a otras ganadoras del premio, como Tres tristes tigres, Cambio de piel ${ }^{32}$ y El obsceno pájaro de la noche. $\mathrm{Y}$, aunque tardíamente, y con no pocos inconvenientes, difundió la narrativa breve de Cortázar en España. En este sentido, su sello dio lugar a una profunda renovación de la literatura española, a la que Barral consideraba estancada en un realismo decimonónico, rural o urbano. No obstante, el esplendor de la firma duró poco: Víctor Seix murió en un accidente en Frankfurt, comenzaron los problemas con la familia Seix y Barral debió dejar la editorial en $1970^{33}$.

El gran editor argentino Arnaldo Orfila Reynal había desempeñado un rol fundamental en el Fondo de Cultura Económica de México. Desempeñó el cargo de Director General durante diecisiete años, elaborando y produciendo uno de los catálogos más notables de nuestra lengua. En 1965, la publicación de un libro irritó a la administración de Díaz Ordaz y a Salvador Azuela, quienes decidieron echar a Orfila de la editorial ${ }^{34}$. Poco después, y habiendo recibido la solidaridad de artistas e intelectuales de todo el mundo, el editor argentino estaba fundando Siglo xxI -la sociedad Siglo xxI Editores S. A. se constituyó oficialmente el 9 de marzo de 1966. La expulsión de Orfila motivó el repudio de buena parte del mundo intelectual y algunos escritores creyeron que debían enviarle títulos para apoyarlo en su nueva empresa. En esa labor, Carlos Fuentes ofició de una suerte de embajador del sello en Europa ${ }^{35}$; él mismo se comprometió a entregarle su 
nueva novela, promesa que cumplió, aunque algo demorada: Zona sagrada. Alejo Carpentier le ofreció a Fuentes la novela que estaba escribiendo, un proyecto que quedó inconcluso: su significativo título iba a ser 1959; sin embargo, y después de un par de títulos en Seix Barral, Carpentier se convertirá, como es sabido, en un autor de Siglo XXI. También Julio Cortázar cumplió con su compromiso y le entregó a Orfila los textos misceláneos de La vuelta al día en ochenta mundos (1967) y último round (1969). Miguel Ángel Asturias, que estaba por esos años publicando sus libros en Losada, le envió El espejo de Lida Sal, editado también en 1967, justo el año en que el guatemalteco ganó el Premio Nobel. Mario Vargas Llosa, acaso por sus compromisos con Seix Barral, y aunque Fuentes dio como firme su intención, nunca envió un libro para la editorial de Orfila. El editor Jorge Herralde solía decir en broma que en sus inicios editoriales «había tenido dos obstáculos de cuidado: Franco y su censura, y Orfila y su Siglo XXI» ${ }^{36}$. Se refería, claro está, a un brillante catálogo que parecía acaparar todas las novedades del vigoroso proceso de transformación estética en literatura y de modernización teórica en las ciencias sociales.

\section{Otros títulos significativos}

1966: Luisa Valenzuela, Hay que sonreír (Americalee); Arturo Jauretche, El medio pelo en la sociedad argentina (Peña Lillo); Juan José Saer, La vuelta completa (Bib. Pop. Constancio Vigil)

1967: Leónidas Lamborghini, La estatua de la libertad (Alba ediciones); Carlos Mastronardi, Memorias de un provinciano (Ediciones Culturales Argentinas); Abelardo Castillo, La casa de ceniza (Estuario); Aldo Pellegrini, Distribución del silencio (Fabril); Aldo Pellegrini, Surrealismo en la Argentina (Instituto Di Tella); Severo Sarduy, De dónde son los cantantes (Joaquín Mortiz); Luisa Valenzuela, Los heréticos (Paidós); Ana M. Barrenechea, La expresión de la irrealidad en Borges (Paidós); Victoria Ocampo, Testimonios, $7^{a}$ serie (Sur).

1968: Salvador Garmendia, La mala vida (Arca); Ernesto Sabato, Tres aproximaciones a la literatura de nuestro tiempo: Robbe-Grillet, Borges, Sartre (Editorial Universitaria de Santiago de Chile); Miguel Briante, Hombre en la orilla (Estuario); AA.VV., Antología consultada de la Joven Poesía argentina (Fabril); Andrés Rivera, El yugo y la marcha (Merlín); Arturo Jauretche, Manual de zonceras argentinas (Peña Lillo); Ezequiel Martínez Estrada, Coplas de ciego. Otras coplas de ciego (Sur); Adolfo Prieto, Literatura y subdesarrollo (Bib. Pop. Constancio Vigil)

1969: José Pedroni, Obra poética, 2 tomos (Rosario, Ed. Biblioteca); Osvaldo Lamborghini, El fiord (Chinatown); Eliseo Verón (ed.) Lenguaje y comunicación social (Nueva Visión); Jorge Lafforgue (comp.) Nueva novela latinoamericana 1 (Paidós); Oscar Masotta, La historieta en el mundo moderno (Paidós); Bernardo Verbitsky, La neurosis monta su espectáculo (Paidós); Antonio Dal Masetto, Siete de oros (Carlos Pérez); Juan Carlos Martelli, Getsemaní (Carlos Pérez); Ernesto Sabato, Itinerario (Sur).

1970: Juan L. Ortiz, En el aura del sauce, 3 tomos (Rosario, Ed. Biblioteca, 1970-1971); Oscar Steimberg, Cuerpo sin armazón (Editores Dos); Hebe Uhart, La gente de la casa rosa (Fabril).

60 Una pregunta estimulante de Miguel Dalmaroni fue el disparador de los artículos que conforman este número: «¿qué era exactamente lo que estaba surgiendo en Buenos Aires?»; y a esta pregunta responde con una hipótesis: «1969' podría representar el momento que reúne a los últimos modernos de la literatura argentina, el corpus en que 
emerge la zona literaria del último gran giro de modernismo cultural ${ }^{37}$. La hipótesis se sustenta en la publicación, durante ese año, de un puñado de libros (a los que, a los fines de reflexionar sobre nuestro tema, añadimos el sello en que se editaron): Cicatrices, de Juan José Saer (Sudamericana); Boquitas pintadas, de Manuel Puig (Sudamericana); El fiord, de Osvaldo Lamborghini (Chinatown); Los poemas de Sidney West, de Juan Gelman (Galerna); Fuego en Casabindo, de Héctor Tizón (Galerna); ¿Quién mató a Rosendo?, de Rodolfo Walsh (Tiempo Contemporáneo). Dalmaroni reconoce que el recorte de este corpus se opera "sobre una masa de títulos mucho más copiosa" (p. 122); de esa masa, menciona a Sagrado, de Tomás Eloy Martínez (Sudamericana), como el arribo a nuestro país de una poética, el realismo mágico, que ya evidenciaba signos de agotamiento; y a Los suicidas, de Antonio Di Benedetto (Sudamericana); Diario de la guerra del cerdo, de Adolfo Bioy Casares (Emecé); y Último round, de Julio Cortázar (Siglo XXI), como representantes de estéticas emergentes en fases históricas anteriores, un modo casi eufemístico de afirmar que para entonces ya eran residuales.

61 Ahora bien, si evaluamos esta hipótesis desde el campo editorial, 1969 no resulta un año particularmente significativo; tomando como referencia el conjunto de libros que menciona Dalmaroni, es sencillo advertir, por un lado, que se publican en sellos heterogéneos y de trayectorias diversas; por otro, que proyectos editoriales caracterizados por su modernidad y dinamismo, como Jorge Álvarez y el CEAL, no aparecen en ese conjunto, lo que los dejaría fuera del protagonismo de ese "último gran giro". Por esta razón, y a los fines de reflexionar sobre esta coyuntura temporal, optamos por ampliar el foco a un período mayor. En consecuencia, estas notas no han pretendido respaldar ni refutar la hipótesis reseñada; más modestamente, solo brindar un panorama de las condiciones materiales de producción que pudieron haber favorecido esa emergencia.

\section{NOTAS}

1. Fuente: Pierre Lagarde, La politique de l'édition du livre en Argentine, Toulouse: Service de Publications de l'Université de Toulouse-Le Mirail, 1981, pp. 52-53.

2. Jorge B. Rivera, «Apogeo y crisis de la industria del libro (1955-1970)», Capitulo. Historia de la literatura argentina, Buenos Aires: Centro Editor de América Latina, vol. 4, 1980, pp. 631-632.

3. Héctor Schmucler postula un análisis similar de los números del período: «Entre 1940 y 1949, en efecto, se editaron en la Argentina 250 millones de ejemplares, frente al prieto bagaje de 22 millones impresos durante el cuatrienio 1936/1939. En el período 1950/1959 la cifra ascendió todavía a 283 millones, volumen que en el momento siguiente (1960/1969) -que coincide con la revitalización de la industria española- decae a 238 millones, lo que nos vuelve a colocar en cantidades inferiores a las consignadas para el período 1940/1949». En «Innovación de la política cultural en la Argentina», AA.VV., ¿Hacia un nuevo orden social en América latina?, Vol. 8, Buenos Aires: CLACSO, Biblioteca de Ciencias Sociales, marzo, 1990, p. 195. Idéntico análisis en Octavio Getino, Las industrias 
culturales en la Argentina. Dimensión económica y políticas públicas, Buenos Aires: Colihue, 1995, pp. 45-46.

4. Raúl H. Bottaro, La edición de libros en Argentina, Buenos Aires: Troquel, 1964, p. 58.

5. Jorge B. Rivera, op. cit., pp. 632-633.

6. Ángel Rama, «El 'boom' en perspectiva», Más allá del boom: literatura y mercado, Buenos Aires: Folios, 1984, pp. 87-88.

7. Jorge B. Rivera, op. cit., p. 637.

8. Según afirma Silvia Sigal, «El aumento de los inscriptos entre 1950, 1960 y 1970 fue considerable en todos los países de la región. Las cifras son: para la Argentina, 82.500, 180.780 y 274.000; para Brasil, 51.000, 95.700 y 430.000; para México, 35.200, 76.900 y 247.600». En Intelectuales y poder en la década del sesenta, Buenos Aires: Puntosur, 1991, p. 86.

9. Uno de los ejemplos más mencionados de la «sinergia» entre proyecto editorial y medios de comunicación es el espacio privilegiado que han tenido los libros de Alfaguara en el periódico $\mathrm{El}$ País, en España (ambos pertenecen al grupo P.R.I.S.A). Algo parecido se ha sugerido respecto del espacio ocupado por los libros y autores de Sudamericana en el semanario Primera Plana: recuérdense, a manera de ejemplo, las tapas dedicadas a Julio Cortázar y a Leopoldo Marechal.

10. Emilio Carilla, Autores, libros y lectores en la literatura argentina, Universidad Nacional de Tucumán: Cuadernos de Humanitas nº 51, 1976, p. 30.

11. Rodolfo A. Borello, «Autores, situación del libro argentino y entorno material de la literatura en la Argentina del siglo XX», Cuadernos Hispanoamericanos, № 322-323, Madrid, abril-mayo de 1977, p. 38.

12. Octavio Getino, op. cit., p. 56.

13. Leandro de Sagastizábal, La edición de libros en la Argentina. Una empresa de cultura, Buenos Aires: Eudeba, 1995, pp. 99-100.

14. Además, Porrúa lanzó en 1954, y en sociedad con Sudamericana, el exitoso sello Minotauro, dedicado al género de ciencia-ficción; su primer título fue Crónicas marcianas, de Ray Bradbury, con prólogo de Borges y traducción del propio Porrúa. El catálogo contó, también, con algunos autores argentinos: 1966: Alberto Vanasco, Memorias del futuro; Emilio Rodrigué, Plenipotencia; 1967: Angélica Gorodischer, Opus dos; Alberto Vanasco, Adiós al mañana. Entre los títulos más destacados de aquellos años, pueden mencionarse El mundo sumergido (1966), de James. G. Ballard; Las cosmicómicas (1967), de Italo Calvino y Remedio para melancólicos (1968), de Ray Bradbury.

15. José Luis de Diego, La otra cara de Jano. Una mirada crítica sobre el libro y la edición, Buenos Aires: Ampersand, 2015, pp. 141-164.

16. Fernando Larraz Elorriaga y José Luis de Diego, «Una conversación con Jorge Lafforgue», La Plata: Orbis Tertius, Universidad Nacional de La Plata, no 22, 2015. En línea: http:// www.orbistertius.unlp.edu.ar/. Consulta: 12/07/2016.

17. Neruda fue un autor que Losada vendió muy bien. En 1944 se editó Veinte poemas de amor y una canción desesperada, el que, hacia 1961, alcanzó el millón de ejemplares vendidos.

18. Un libro de Sartre que vende 6.000 ejemplares en dos semanas es, visto desde el presente, un dato completamente inverosímil. Sin embargo, en aquel contexto todo resultaba diferente. Cuando la bibliografía insiste en la impronta sartreana que marcó a los sesenta, no se suele mencionar la venta de sus libros, que no es un dato para nada desdeñable. Por ejemplo, la editorial Tiempo Contemporáneo publicó en un año tan conflictivo como 1975 el primer tomo del 
extenso estudio de Sartre sobre Flaubert, El idiota de la familia, un libro que, por su dimensión y características, hoy no parecería en absoluto rentable.

19. Antonio Lago Carballo y Nicanor Gómez Villegas (eds.), Un viaje de ida y vuelta. La edición española e iberoamericana (1936-1975), Buenos Aires: FCE/Siruela, 2007, p. 122.

20. Leandro de Sagastizábal, op. cit., pp. 89-90.

21. Ángel Rama, op. cit., pp. 67-68.

22. Menciono las colecciones más relacionadas con la literatura argentina correspondientes al período que nos ocupa. Para un análisis del vasto catálogo del CEAL, véase Judith Gociol (comp.), Más libros para más. Colecciones del Centro Editor del América Latina, Buenos Aires: Biblioteca Nacional, 2007.

23. En Judith Gociol (comp.), op. cit., p. 25. Que la primera colección literaria del CEAL se inicie con un título tan poco «popular» como Papeles de recienvenido, pone de manifiesto la riqueza del proyecto y la audacia de la propuesta. Sarlo ha referido que «Boris y Achával tuvieron una pelea homérica por Macedonio Fernández» (Ibid.).

24. A los fines de nuestro trabajo, resulta de particular relevancia la colección Narradores de Hoy, también dirigida por Gregorich, en el que pudieron publicar sus primeras obras muchos de los jóvenes escritores de entonces. Sin embargo, la colección se dio a conocer en 1971, fuera del período que nos hemos impuesto para este artículo.

25. Susana Zanetti, quien fuera activa protagonista en ambas empresas, analiza con lucidez los cambios producidos desde el proyecto de Eudeba a las políticas del CEAL en «Canon y mercado. La Serie del Siglo y Medio y Capítulo», La Plata: Orbis Tertius Universidad Nacional de La Plata, $\mathrm{n}^{\mathrm{o}}$ 12, 2006. En línea: http:// www.orbistertius.unlp.edu.ar/issue/view/102 . Consulta: 12/07/2016

26. Ana Mosqueda, «La editorial Jorge Álvarez, cenáculo de los sesenta», La Biblioteca, $\mathrm{n}^{\circ}$ 4-5, Buenos Aires, Biblioteca Nacional, verano de 2006, pp. 482-489.

27. Jorge Álvarez, Memorias, Buenos Aires: Libros del Zorzal, 2013.

28. Guillermo David, «Pedir peras», Pidamos peras a Jorge Álvarez, Catálogo, Buenos Aires: Biblioteca Nacional, marzo de 2012.

29. Supervivencia no exenta de obstáculos: durante la dictadura, Miler y Divinsky se vieron obligados a dirigir la editorial desde su exilio en Venezuela, entre 1977 y 1983.

30. Daniel Divinsky, «Breve historia de Ediciones de la Flor. Editar en la Argentina: ¿un oficio insalubre?», La Biblioteca, № 4-5, Buenos Aires, Biblioteca Nacional, verano de 2006, p. 435.

31. La edición facsimilar de Los Libros fue editada por la Biblioteca Nacional en 2011.

32. La novela de Carlos Fuentes fue prohibida por la censura española y debió editarse a través de Joaquín Mortiz en México y de Sudamericana en Argentina.

33. Sobre Seix Barral, véase Xavier Moret, Tiempo de editores. Historia de la edición en España, 1939-1975, Barcelona: Destino, 2002, pp. 179-253.

34. Sobre el despido de Orfila y su contexto, véase Gustavo Sorá, «Edición y política. Guerra fría en la cultura latinoamericana de los años 60», Revista del Museo de Antropología, № 1, Universidad Nacional de Córdoba, 2008, pp. 97-114.

35. En este sentido, puede consultarse Carlos Fuentes y Arnaldo Orfila Reynal, Cartas cruzadas, México: Siglo XXI, 2013.

36. Jorge Herralde, El optimismo de la voluntad. Experiencias editoriales en América Latina, México: FCE, 2009, p. 92. 
37. Miguel Dalmaroni, «Historia literaria y corpus crítico (aproximaciones williamsianas y un caso argentino)», Boletín del Centro de Estudios de Teoría y Crítica Literaria, № 12, Universidad Nacional de Rosario, diciembre de 2015, p. 124.

\section{RESÚMENES}

Se postula una sumaria caracterización del mercado editorial de literatura durante los últimos años de la década del sesenta: ciclos de producción de libros, ejemplares impresos, tirajes promedio, volúmenes exportados. Se analizan las razones de la primavera editorial que se consolidó con la figura «boom del libro argentino»: las posibles causas de la demanda de un nuevo público lector, y sus efectos en la comercialización de los impresos y en la profesionalización de los autores. A partir del relevamiento de la nómina de títulos publicados entre 1966 y 1970, se caracterizan las políticas editoriales de los principales sellos, desde los ya consolidados en la década del treinta (Sudamericana, Losada, Emecé) hasta los emergentes en la coyuntura que nos ocupa (Centro Editor de América Latina, Jorge Álvarez, De la Flor, Galerna, Tiempo Contemporáneo).

Nous proposons une caractérisation sommaire du marché de l'édition de littérature de la fin des années soixante: cycles de production des livres, exemplaires imprimés, tirages moyens, volumes exportés. Nous analysons les raisons du «printemps de l'édition» qui s'est consolidé avec la figure «boom du livre argentin»: les causes possibles de la demande d'un nouveau public lecteur, et leurs effets sur la commercialisation des imprimés et sur la professionnalisation des auteurs. À partir de la recension du répertoire de titres publiés entre 1966 et 1970, nous caractérisons les politiques d'édition des principales maisons d'édition, celles déjà consolidées depuis les années trente (Sudamericana, Losada, Emecé) et celles qui émergent dans le contexte qui nous occupe (Centro Editor de América Latina, Jorge Álvarez, De la Flor, Galerna, Tiempo Contemporáneo).

The study proposes a concise characterization of the book industry in the literary field during the late 1960s: cycles in book production, printed copies, print runs, exported volumes. It analyses the reasons for the publishing boom known as the «Argentine-book boom»: the possible causes for the demand of a new reading public, and its effects on the commercialization of published matter and on the professionalization of writers. On the basis of the data-gathering of book titles published between 1966 and 1970, the main houses' publishing policies are characterized, from those consolidated in the 1930s (Sudamericana, Losada, Emecé) to those emerging in the studied period (Centro Editor de América Latina, Jorge Álvarez, De la Flor, Galerna, Tiempo Contemporáneo).

\section{ÍNDICE}

Palabras claves: mercado editorial, literatura, Argentina, década del sesenta, editoriales y editores

Mots-clés: marché éditorial, littérature, Argentine, années 1960, maisons d'édition et éditeurs

Keywords: book industry, literature, Argentina, 1960s, publishing houses and publishers 


\section{AUTOR}

\section{JOSÉ LUIS DE DIEGO}

Universidad Nacional de La Plata

lamy@speedy.com.ar 